\title{
Tibetan Plateau heating as a driver of monsoon rainfall variability in Pakistan
}

\author{
Ziqian Wang ${ }^{1}$ (D) Song Yang ${ }^{1} \cdot$ Anmin Duan $^{2} \cdot$ Wei Hua $^{3} \cdot$ Kalim Ullah $^{4} \cdot$ Senfeng Liu ${ }^{2}$
}

Received: 5 June 2018 / Accepted: 15 October 2018 / Published online: 19 October 2018

(c) The Author(s) 2018

\begin{abstract}
Pakistan summer monsoon rainfall consists of a large portion of the local annual total rainfall, and in the recent monsoon seasons, prolonged periods of anomalous rainfall and excessive flooding have appeared in Pakistan. A full understanding of the monsoon rainfall variability is important for the sustainable development of the country. Based on multiple data analyses and the weather research and forecasting model, the potential impact of Tibetan Plateau (TP) heating on the interannual variability of Pakistan monsoon rainfall is investigated. It is observed that a significant negative relationship exists between the thermal forcing over the southeastern TP and Pakistan monsoon rainfall in July-August. Both the data analyses and model sensitivity experiments identify that the TP heating drives a Rossby wave response in the upper atmosphere characterized with an anticyclonic anomaly over the southern TP but a cyclonic anomaly to the north. This dipole pattern of anomalous circulation induces an evident upper-level convergence over Pakistan, corresponding with remarkable vertical sinking motion. Meanwhile, in the lower troposphere, the TP heating causes anomalous westerly wind along the Himalayas over the northern India continent. Such westerly anomaly further induces less water vapor transport into Pakistan from the Bay of Bengal. Therefore, both the dynamic and thermodynamic processes regulated by positive TP heating are not beneficial for the occurrence of monsoon rainfall in Pakistan. This study proposes a new potential mechanism in which TP heating acts as a driver of Pakistan monsoon rainfall variability on interannual time scales.
\end{abstract}

Keywords Pakistan monsoon rainfall $\cdot$ Tibetan Plateau $\cdot$ Thermal forcing $\cdot$ Interannual variability

\section{Introduction}

Ziqian Wang

wangziq5@mail.sysu.edu.cn

Song Yang

yangsong3@mail.sysu.edu.cn

1 School of Atmospheric Sciences, Guangdong Province Key Laboratory for Climate Change and Natural Disaster Studies, Sun Yat-sen University, 135 West Xingang Road, Guangzhou 510275, China

2 State Key Laboratory of Numerical Modeling for Atmospheric Sciences and Geophysical Fluid Dynamics, Institute of Atmospheric Physics, Chinese Academy of Sciences, Beijing, China

3 Plateau Atmosphere and Environment Key Laboratory of Sichuan Province, School of Atmospheric Sciences, Chengdu University of Information Technology, Chengdu, China

4 Department of Meteorology, COMSATS Institute of Information Technology, Islamabad, Pakistan
Pakistan is typically arid and semi-arid with diversified climate conditions. As the greatest contributor to the annual total rainfall, the summer monsoon rainfall is critical for freshwater resource, agriculture production, and overall economy of the country (Latif et al. 2017). The monsoon rainfall in Pakistan is a western extension of the South Asian summer monsoon system (Hussain and Lee 2016), but it mainly occurs in July and August (Fig. 1b). Fluctuations in the monsoon rainfall often lead to devastating floods and droughts (Adnan et al. 2016). For instance, a historic and catastrophic flooding event happened in Pakistan during July-August of 2010, which resulted loss of life and property and the related agricultural crisis lasted for years (Webster et al. 2011; Houze et al. 2011).

Since the worst flooding in 2010, a number of studies on the physical mechanisms of Pakistan monsoon rainfall variability have been conducted. In general, two factors are emphasized: one is the large-scale atmospheric disturbances 
(a) Terrain height

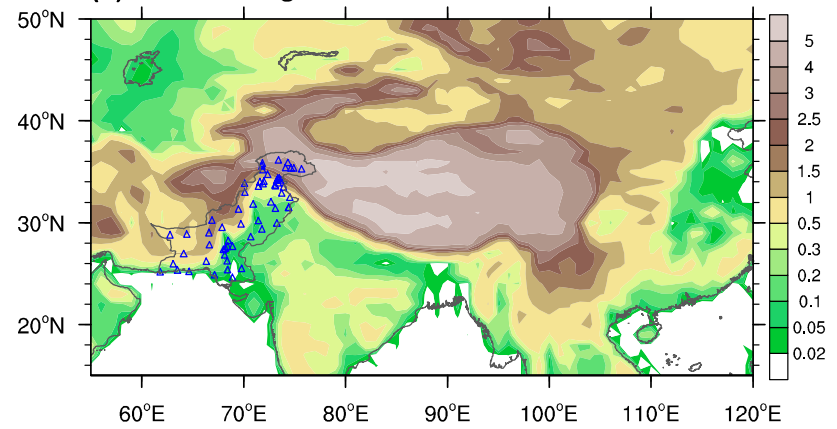

(b) Monthly rainfall

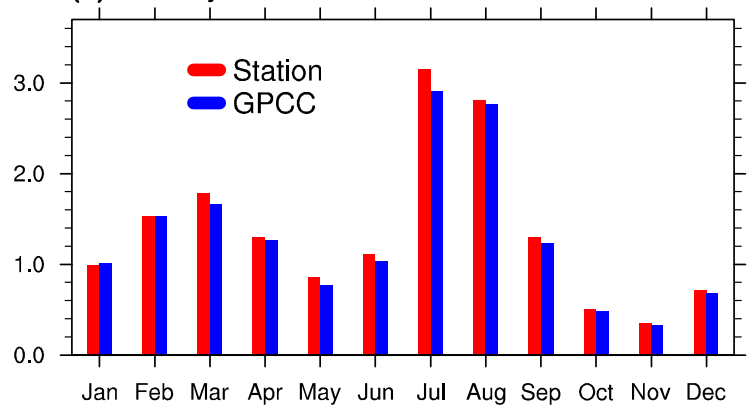

Fig. 1 a Terrain height (unit: $\mathrm{km}$ ) and the locations of 60 Pakistan meteorological stations (denoted by the blue triangles). b Monthly mean rainfall (unit: $\mathrm{mm} \mathrm{day}^{-1}$ ) averaged from the 60 stations during 1980-2014. The red and blue bars represent the station observations and GPCC data

from the middle and high latitudes (e.g., Lau and Kim 2012; Galarneau et al. 2012), and the other is the monsoon surges or depressions from tropical regions (e.g., Houze et al. 2010; Galarneau et al. 2012; Rasmussen et al. 2015). Meanwhile, Hong et al. (2011) claimed that the dominant factor resulting in the severe flooding in Pakistan was the interaction between tropical monsoon synoptic oscillations and extratropical disturbances downstream of the atmospheric blocking. This tropical-extratropical interaction was also proposed by Lau and Kim (2012). The climatological relationship between the summer heavy rainfall in Pakistan and northwestern India and the atmospheric blocking over Eurasian continent has also been investigated (Yamada et al. 2016). In particular, the high persistent blocking frequency in western Russia tended to bring about more rainfall in Pakistan and northwestern India.

Geographically, Pakistan is located at the southwest of the Tibetan Plateau (TP) with a complex terrain (Fig. 1a). It is well known that the TP, the highest plateau in the world with an average topography height of $>4 \mathrm{~km}$, exerts significant impacts on the weather and climate over many places of the world through both mechanical and thermaldynamical effects (e.g., Kitoh 2004; Yanai and Wu 2006; Wu et al. 2007, 2012; Okajima and Xie 2007; Boos and Kuang 2010; Duan et al. 2012; Wang et al. 2014). Particularly in the summer time, the TP serves as a huge heat source, which can directly heat the air in the middle troposphere (Ye and Gao 1979; Zhao and Chen 2001b). However, the potential relationship between the TP thermal forcing and Pakistan summer monsoon rainfall has rarely received attention. Climatologically, the TP thermal forcing tends to suppress the summer rainfall in the area around Pakistan, as suggested by numerical experiments [see Fig. 4h in Wang et al. (2016) and Fig. $3 b$ in Wu et al. (2016)]. However, such a relationship is still unclear in observational data.

Previous studies on Pakistan summer rainfall have been mostly focused on the details of individual events separately, especially on the above-reviewed flooding event in 2010 (e.g., Houze et al. 2011; Galarneau et al. 2012; Rasmussen et al. 2015). With the growing attention on the floods and droughts in Pakistan, further and fully understanding the variability of summer monsoon rainfall is an urgent issue, both scientifically and socially. Especially, a skillful prediction of monsoon rainfall is the major prerequisite of agricultural productivity and economic stability, particularly to the developing countries like Pakistan.

In this study, our finding raises the intriguing possibility that the TP heating can significantly regulate the summer monsoon rainfall in Pakistan on interannual time scale. We will show the detailed physical mechanism from both data analysis and modeling investigation. The remainder of this paper is organized as follows. In Sect. 2, the data, methodology, and model are described briefly. Sections 3 and 4 present the data diagnosis and modeling results, and further explain how the TP heating affects Pakistan monsoon rainfall. Finally, a summary and a further discussion are provided in Sect. 5.

\section{Data, methodology, and model}

Monthly precipitation data for the period of 1980-2014 from 60 meteorological stations of the Pakistan Meteorological Department (PMD) is used, and the locations of these stations are marked by the blue triangles in Fig. 1a. Meanwhile, another monthly grid rainfall data is extracted from the Global Precipitation Climatology Centre (GPCC) with a horizontal resolution of $1.0^{\circ} \times 1.0^{\circ}$ (Schneider et al. 2014). The GPCC, a widely-used rainfall data set over land, is based on the quality-controlled raingauge data drawn from 67,200 stations worldwide that had available data of 10 or more years. For Pakistan, the monthly mean rainfall from the above two data sets present a basically consistent annual cycle (Fig. 1b). Moreover, there exists a high correlation between the two data sets for the interannual rainfall variability in Pakistan (Adnan et al. 2016). Also employed are the monthly atmospheric fields from the long-term Japanese 55-year Reanalysis (JRA-55, Kobayashi et al. 2015), which 
has a horizontal resolution of $1.25^{\circ} \times 1.25^{\circ}$. This data set extends from $1000 \mathrm{hPa}$ to $1 \mathrm{hPa}$, with 37 vertical pressure levels. We choose JRA-55 to do the atmospheric diagnose also because its atmospheric circulation and diabatic heating fields agree well with those derived from station and satellite observations on the interannual time scale over the TP and surrounding areas (Hu and Duan 2015).

This study is focused on the peak boreal summer (July-August), for the period of 1980-2014, because the Pakistan monsoon rainfall is largest in these 2 months (Fig. 1b). Based on the PMD rainfall data set, a Pakistan monsoon rainfall index (PMRI) on the interannual variability is defined as the averaged summer (July-August) rainfall from the observed values of 60 stations. Besides, the TP heating is represented by the vertically-integrated atmospheric diabatic heating, which is synthesized from different heating rates. The expression of total diabatic heating $(Q)$ can be written as

$Q=L H+V D H+R H$,

where $L H$ is atmospheric latent heating, which includes convective heating rate and large scale condensation heating rate; $V D H$ is vertical diffusion heating rate; and $R H$ is radiative heating rate, which covers long wave and short wave radiation. All of these heating rates can be obtained from JAR-55 data set, with a unit of $\mathrm{K} \mathrm{day}^{-1}$. Then, $\langle Q\rangle$ denotes the vertical integration of diabatic heating, which is expressed as

$\langle Q\rangle=\frac{C_{p}}{g} \int_{p_{t}}^{p_{s}} Q d p$.

Here $g$ is acceleration due to gravity, $C_{p}$ is the specific heat of dry air at constant pressure, and $p_{s}$ is surface pressure. The pressure of top layer $p_{t}$ is equal to $100 \mathrm{hPa}$. After the integration, unit of $\langle Q\rangle$ is $\mathrm{W} \mathrm{m}^{-2}$.

The linear correlation and regression methods are applied to detect the relationship between the TP heating and Pakistan monsoon rainfall along with the associated atmospheric process. According to Wilks (1995), the simple linear regression is expressed as $Y_{i}=a+b X_{i}(i=1,2,3, \ldots, n)$, where $a$ and $b$ are the regression constant and linear regression coefficient, respectively. In this study, the independent variable $X_{i}$ is normalized time series of diabatic heating over the southeastern TP with a sample size $n$, and the dependent variable $Y_{i}$ is the spatial pattern of atmospheric process (e.g., wind, vertical velocity, upper-level divergence, or moisture transport). Then, the regression coefficient $b$ is finally calculated (Eq. (3)) to describe the linear relationship between $X_{i}$ and $Y_{i}$. It should be noted that all the data analyses in this study are performed on linear detrended time series, as the interannual time scale is emphasized. $\mathrm{b}=\frac{\sum_{i=1}^{n} X_{i} Y_{i}-\frac{1}{n}\left(\sum_{i=1}^{n} X_{i}\right)\left(\sum_{i=1}^{n} Y_{i}\right)}{\sum_{i=1}^{n} X_{i}^{2}-\frac{1}{n}\left(\sum_{i=1}^{n} X_{i}\right)^{2}}$

The weather research and forecasting (WRF) model version 3.4.1 (Skamarock et al. 2008) is used to better understand the analysis results. The model has been employed widely as a regional climate model to simulate the variations of the Asian summer monsoon (e.g., Wang et al. 2014, 2017b; Raju et al. 2015), with proved performance. Compared with global models, the WRF has higher resolutions that can represent topography and land surface processes more accurately (Gao et al. 2016). The physical packages incorporated in the WRF model for this study include the WRF Single-Moment 6-Class microphysics scheme, the Grell-Devenyi convective scheme, the Noah land surface model, the BouLac planetary boundary layer scheme, the Goddard shortwave scheme, and the Rapid Radiative Transfer Model for longwave radiation. More details of these physical schemes can be found in the user's guide of the WRF (http://www2.mmm.ucar.edu/wrf/users/docs/user_ guide_V3/). The initial state of the atmosphere and the lateral boundary conditions (updated every $6 \mathrm{~h}$ ) are obtained from the Final Analysis of the National Centers for Environmental Prediction (NCEP, http://rda.ucar.edu/datasets/ds083 .2/). The SST forcing data set used in this WRF model is the Optimum Interpolation SST (OISST, Reynolds et al. 2007) from the National Oceanic and Atmospheric Administration, which is updated daily. Further detailed information about the experimental design will be depicted in Sect. 4 .

\section{Observational features}

Figure 2a shows the spatial distribution of climatological summer (July-August) mean rainfall in Pakistan based on the observations from 60 PMD stations. The station data are transformed into grid data through the iterative improvement objective analysis before drawing the spatial plot. It is noted that the observed monsoon rainfall gradually reduces from the northeast to the southwest and rainfall is most intense in northern Pakistan, with a maximum amount of $>8 \mathrm{~mm} \mathrm{day}^{-1}$. This pattern is mainly induced by the westward transport of moisture flux along the Himalayas from the northern Bay of Bangle (Lau and Kim 2012). More water vapor is accumulated in northern Pakistan than in the south during the monsoon season. It should be also noted that a sub-center of monsoon rainfall exists in southeastern Pakistan about $\sim 3 \mathrm{~mm} \mathrm{day}^{-1}$. But the moisture source for this sub-center is different, which is from the northern Arabian Sea, in conjunction with a relatively much weaker intensity (figure not 


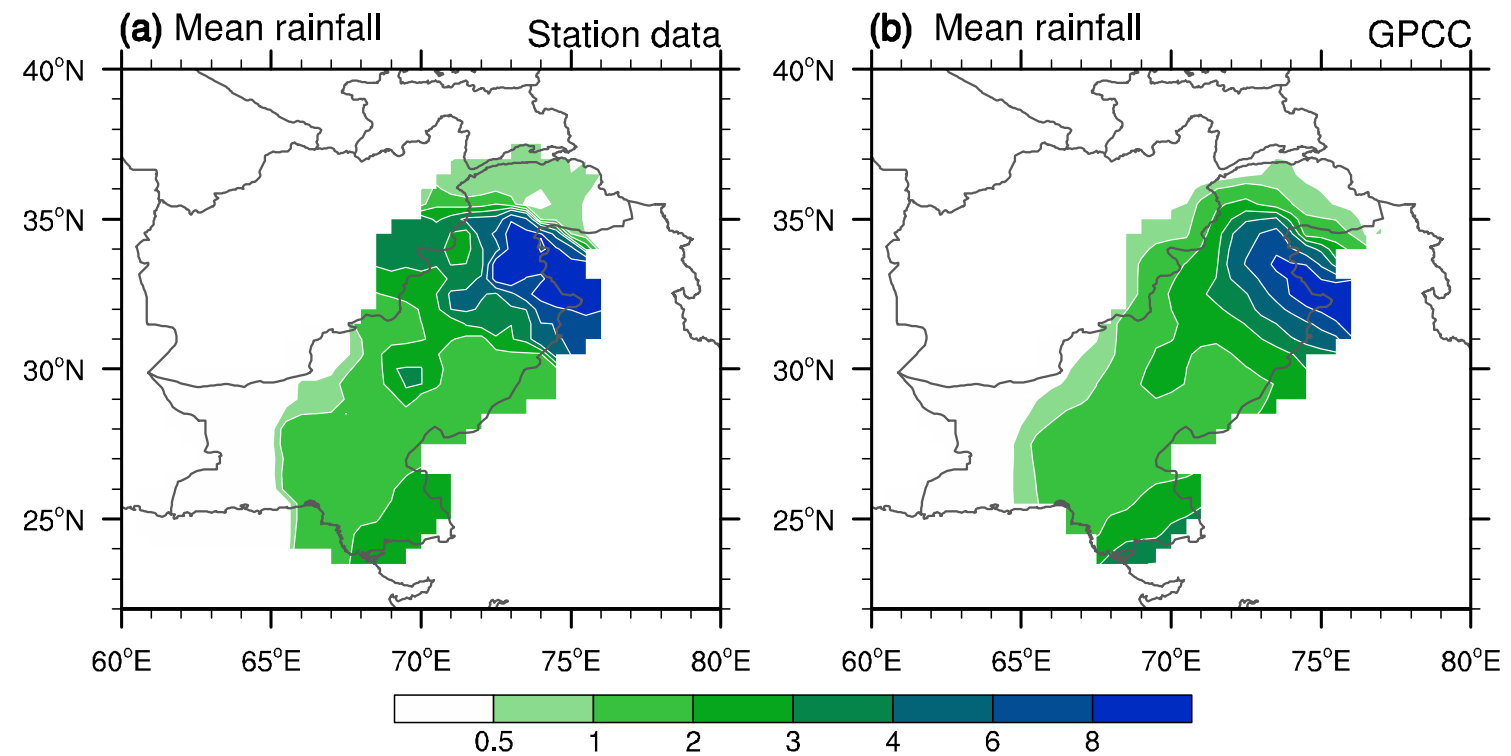

(c) Rainfall variance Station data

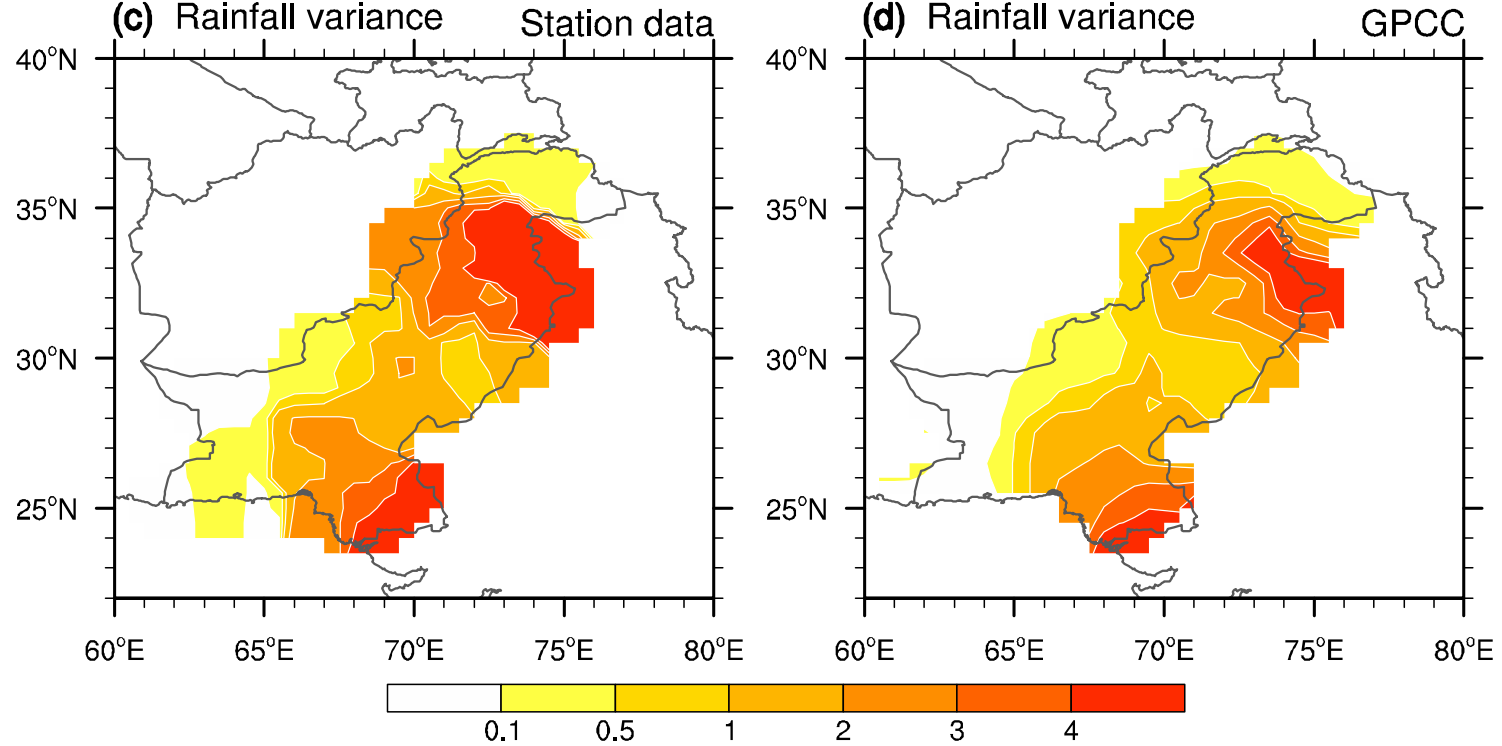

Fig. 2 Spatial patterns of the mean Pakistan monsoon rainfall (unit: $\mathrm{mm} \mathrm{day}^{-1}$ ) in July-August during 1980-2014. a Based on station data and $\mathbf{b}$ based on the GPCC data. c-d The corresponding variances (unit: $\mathrm{mm}^{2}$ day $^{-2}$ ) with the linear trend excluded

shown). Additionally, the corresponding rainfall variance is presented in Fig. 2c, which shows that two significant centers of rainfall variance $\left(>4 \mathrm{~mm}^{2} \mathrm{day}^{-2}\right)$ in northern and southeastern Pakistan respectively, suggesting strong year-to-year fluctuations of the monsoon rainfall. In other words, the significant interannual variability also gives an implication that the disastrous floods or droughts are more likely to arise in those two regions of Pakistan. Such as the worst flooding event in 2010 (Houze et al. 2011), which was mainly occurred in northern Pakistan. Similar results are obtained from the GPCC data set (Fig. 2b, d), which are reflected by both the spatial patterns and the magnitude of values, indicating that the GPCC rainfall data is credible for studying the Pakistan monsoon rainfall variability.

According to Sect. 2, PMRI is defined as the mean rainfall values of the PMD 60 stations in July and August. Figure 3 a provides the interannual correlation coefficients between the PMRI and the homochronous GPCC rainfall. The significant and uniform positive coefficients in Pakistan and its surrounding areas indicate that the yearly variations of rainfall are consistent in these regions, one of reasons that some previous studies preferred to consider Pakistan and northwestern India as a whole region when investigating the regional climate variability (e.g., Bollasina and Nigam 2011; Yamada et al. 2016). On the other hand, obviously 
(a) Interannual correlation

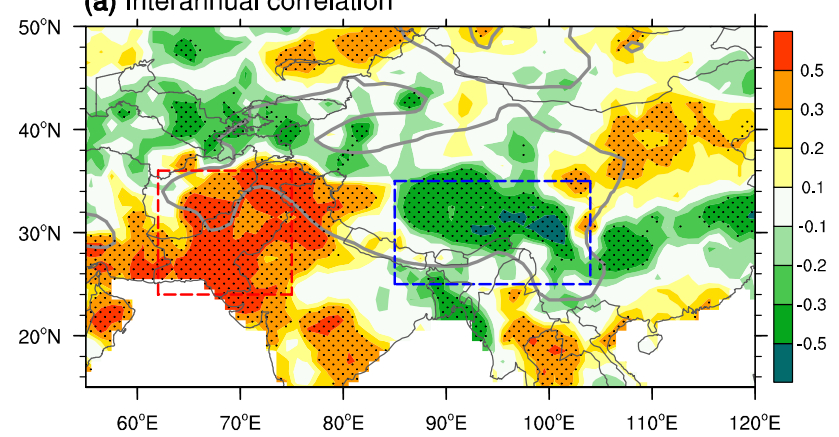

(b) Interannual variability

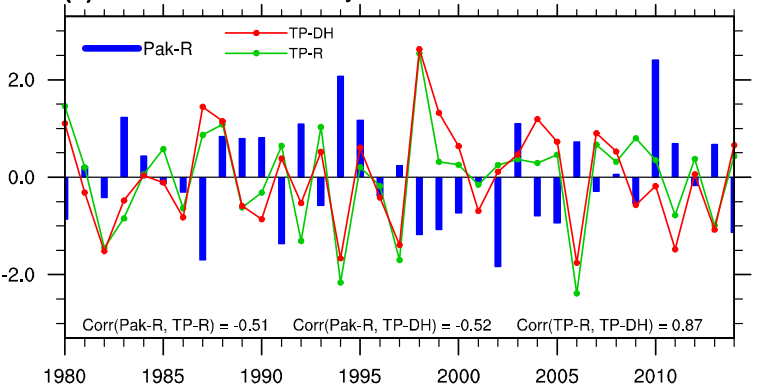

Fig. 3 a Interannual correlation coefficient between the Pakistan monsoon rainfall index and GPCC rainfall in July-August during 1980-2014. Stippling indicates the values $>90 \%$ confidence level and the bold gray lines denote the topographic height of $1500 \mathrm{~m}$. b Normalized time series of Pakistan monsoon rainfall (blue bars, based on the GPCC data) averaged over the red box shown in a, and rainfall (green curve, based on the GPCC data) and diabatic heating (red curve, based on the JRA55 data) over the southeastern TP (see the blue box in a). The linear trends of all variables have been excluded

negative correlation coefficients appear in the southeastern TP (Fig. 3a), indicating that positive PMRI always corresponds with less TP summer rainfall. It should be noted that the climatological mean rainfall is most intense over the southeastern TP in summertime, together with maximum rainfall variance over this area compared to the whole TP region [see Figs. 2, 4 in Wang et al. (2017a)].

It is known that the atmospheric latent heating associated with TP rainfall dominates in the total diabatic heating in summertime (e.g., Ye and Gao 1979; Hu and Duan 2015; Jiang et al. 2016; Wang et al. 2018). For the southeastern TP $\left(25^{\circ} \mathrm{N}-35^{\circ} \mathrm{N}, 85^{\circ} \mathrm{E}-104^{\circ} \mathrm{E}\right)$ where the topography is above $1500 \mathrm{~m}$, we define a TP heating (rainfall) index as the areaaveraged diabatic heating (rainfall) based on the JRA-55 (GPCC) data. Undoubtedly, there is a very close relationship between the two TP indexes on the interannual time scale (with a correlation coefficient of 0.87 as shown in Fig. 3b). On the other hand, the Pakistan monsoon rainfall is highly correlated not only with the rainfall over the southeastern TP (Fig. 3a, b), but also with the TP heating (Fig. 3b). Their interannual correlation coefficients are -0.51 and -0.52 , respectively; both of which significantly exceed the $99 \%$ confidence level.
From the foregoing analyses, it is identified that the Pakistan monsoon rainfall is significantly correlated with the TP heating in July-August. While the TP thermal forcing can substantially regulate the changes in weather and climate over its surrounding areas (e.g., Zuo et al. 2011; Duan et al. 2012; Jiang and Ting 2017), a question arises: does the TP heating act as a driver of the monsoon rainfall variability in Pakistan? To answer this question, we further compute the regression patterns of atmospheric circulation and moisture transport associated with the TP heating (Fig. 4). Corresponding with positive TP heating, a strong anticyclonic anomaly appears at the upper troposphere over the southern TP (Fig. 4a). This result matches with the previously reported patterns (e.g., Duan and Wu 2005; Wang et al. 2016), aroused possibly by the TP thermal forcing. Conversely, to the north of the anticyclonic anomaly, there exists a cyclonic circulation. Under the south-north distribution of anticyclonic and cyclonic anomalies, an anomalous convergence generates at the upper troposphere over Pakistan (Fig. 4a). As a consequence, strong vertical sinking motion is accompanied (Fig. 4b), which is not beneficial for the occurrence of monsoon rainfall over the area of Pakistan. Additionally, Fig. 4c shows significant anomalous lower-tropospheric westerly wind along the Himalayas and over the northern India continent under the background of positive TP heating. The westerly wind anomalies suppress water vapor transport from the Bay of Bangle, and anomalous divergence of moisture flux appears in the Pakistan area (Fig. 4d). Overall, when the thermal forcing over the southeastern TP is strong, both dynamic and thermodynamic conditions tend to weaken the monsoon rainfall in Pakistan.

\section{Numerical experiments}

The above data analysis implies that the TP heating has a potential regulation on the summer monsoon rainfall in Pakistan, which calls for a further investigation through numerical simulations. In this section, the WRF model is chosen to conduct three groups of experiments.

\subsection{Experimental design}

Figure 5a shows the model domain, which covers most of Asia and the adjacent oceans with the Lambert projection (133 grid points in latitude and 195 grid points in longitude) centered at $30^{\circ} \mathrm{N} / 90^{\circ} \mathrm{E}$ (a buffer zone includes 5 grid points). The WRF model has a 45-km horizontal resolution and 35 vertical layers with a prescribed model top at $50 \mathrm{hPa}$. Three ensemble experiments are performed and each incorporates 11 cases (2000-2010) with initial conditions set at 0000 UTC of 1 June. The integration time is 3 months, i.e., every case ends at 1800 UTC of 31 August. 

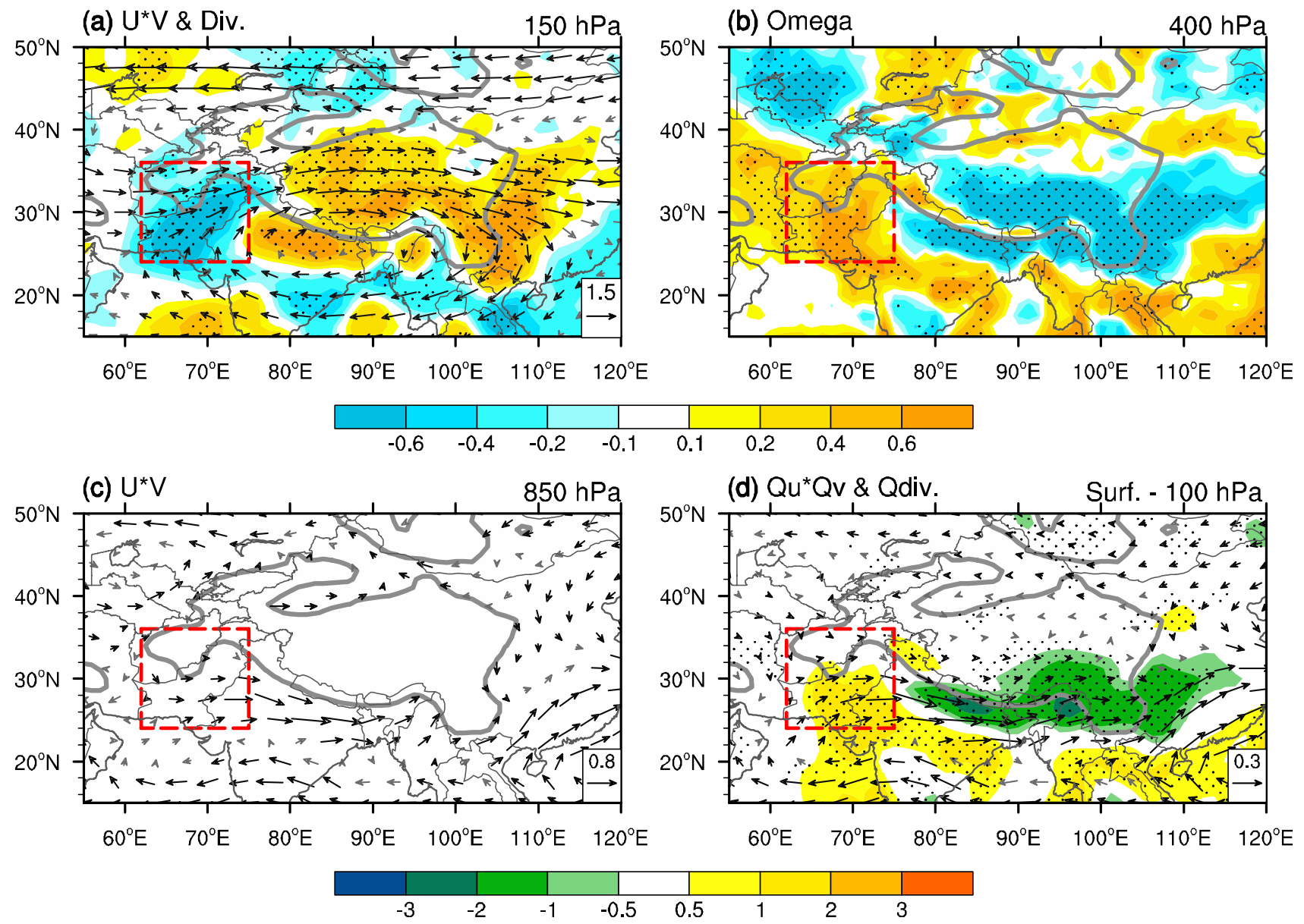

Fig. 4 a Regression patterns of 150-hPa wind (vectors, unit: $\mathrm{m} \mathrm{s}^{-1}$ ) and divergence (shading, unit: $10^{-6} \mathrm{~s}^{-1}$ ) against the TP heating index in July-August during 1980-2014. b As in (a), but for the 400-hPa vertical velocity (unit: $10^{-2} \mathrm{~Pa} \mathrm{~s}^{-1}$ ). c As in (a), but for the 850 $\mathrm{hPa}$ wind (unit: $\mathrm{m} \mathrm{s}^{-1}$ ). d As in (a), but for the vertically integrated $(1000-100 \mathrm{hPa})$ moisture flux transport (vectors, unit: $\mathrm{kg} \mathrm{m}^{-1} \mathrm{~s}^{-1}$ ) and the corresponding divergence (shading, unit: $10^{-7} \mathrm{~kg} \mathrm{~m}^{-2} \mathrm{~s}^{-1}$ ).
The linear trends of all variables have been excluded. Stippling indicates the values $>90 \%$ confidence level for the variables represented by shading, and the vectors significantly above the $90 \%$ confidence level are plotted in black color. The bold gray lines denote the topographic height of $1500 \mathrm{~m}$ and the dashed red box denotes the general region of Pakistan (a) Model domain

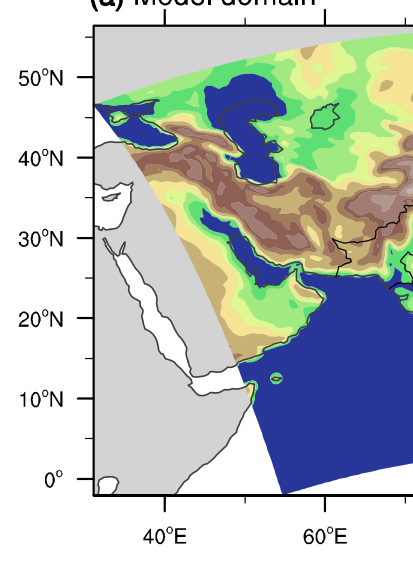

Fig. 5 a The selected domain of the WRF model and the elevation of orography (shading, unit: $\mathrm{km}$ ). b Vertical profiles of atmospheric latent heating (unit: $\mathrm{K} \mathrm{day}^{-1}$ ) over the southeastern TP where the (b) TP latent heating

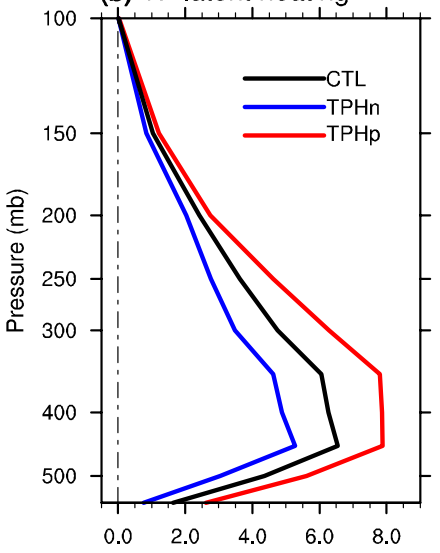

topography is above $1500 \mathrm{~m}$ (see the red rectangular box in a) in different experiments 
Table 1 Experimental design

\begin{tabular}{ll}
\hline Experiments & Details \\
\hline CTL & Normal \\
TPHp & Adding 2.0 SD atmos- \\
& pheric latent heating \\
& profile over the south- \\
& eastern TP \\
& Removing 2.0 SD \\
TPHn & atmospheric latent \\
& heating profile from the \\
& southeastern TP \\
\hline
\end{tabular}

$S D$ standard deviation on the interannual variability

Table 1 gives the details of experimental design. The normal experiment with the WRF model is named the control run (CTL). The WRF model not only simulates the mean rainfall successfully over the broad Asian monsoon region (e.g., Wang et al. 2016, 2017b), but also reproduces the regional summer rainfall reasonably in Pakistan (Fig. 6). The CTL run well captures both the mean rainfall and the corresponding variance as the observed shown in Fig. 2, although the sub-center of rainfall variance in southeastern Pakistan appears somewhat weaker (Fig. 6b). Moreover, comparing with the results from JRA-55 reanalysis data, the CTL run also reproduces the upper and lower-level atmospheric circulation and air temperature reasonably (figure not shown). To illustrate the effect of TP heating on Pakistan monsoon rainfall, sensitivity experiments of positive/negative TP heating are conducted, named TPHp and TPHn respectively (Table 1). Since the atmospheric latent heating dominates in the total heating over the TP in summer (e.g., Ye and Gao 1979; Hu and Duan 2015; Jiang et al. 2016; Wang et al. 2018), only the latent heating anomaly is considered in the sensitivity experiments for simplicity. In the positive (negative) TP heating experiment, from 0000 UTC of 1 July, an anomalous atmospheric latent heating profile is added (removed) over (from) the southeastern TP $\left(25^{\circ} \mathrm{N}-35^{\circ} \mathrm{N}\right.$, $85^{\circ} \mathrm{E}-104^{\circ} \mathrm{E}$ ) where the topography is above $1500 \mathrm{~m}$. The anomalous heating profile is quantified by the 2.0 standard deviation (SD) of the interannual variability of atmospheric latent heating in the JRA-55 data during 1980-2014. This magnitude of heating anomaly is relatively realistic, because 2.0 SD can be observed in the yearly variations of TP heating (such as the year of 1998 in Fig. 3b). Figure 5b shows the area-averaged atmospheric latent heating profiles over the southeastern TP in the three experiments in July and August.

\subsection{Modeling results}

The differences between the two sensitivity experiments with positive (TPHp) and negative (TPHn) TP heating anomalies are used to illustrate the direct influences of TP thermal forcing on Pakistan monsoon rainfall and associated atmospheric circulation (Figs. 7, 8). Strong heating over the southeastern TP can substantially enhance the South Asian high characterized by an anomalous anticyclone in the upper troposphere (Fig. 7a). Meanwhile, to the north of this anticyclonic response, an obvious cyclonic anomaly generates. Such cyclonic anomaly can be viewed as part of a Rossby wave train originating from the anticyclonic anomaly over the southern TP due to its thermal forcing (Wang et al. 2008, 2014). The south-north distribution of anticyclonic and cyclonic responses due to the TP heating effect is basically consistent with the result from data diagnosis (Fig. 4a). Under this situation, significant upper-level convergence is aroused over Pakistan (Fig. 7a), further corresponding with remarkable vertical sinking motion (Fig. 7b, c).

Furthermore, positive TP heating can trigger a significant westerly anomaly along the south foot of TP in the lower
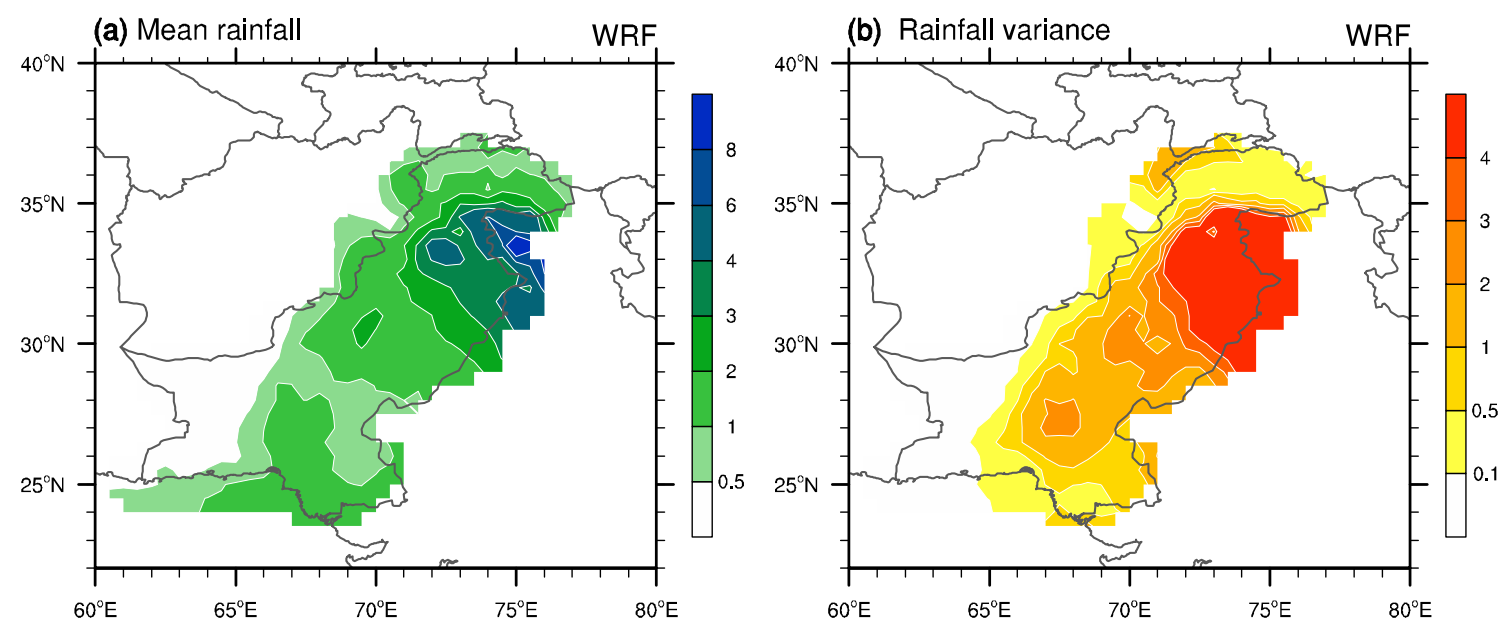

Fig. 6 As in Fig. 2, but for the modeling results from the CTL experiment 


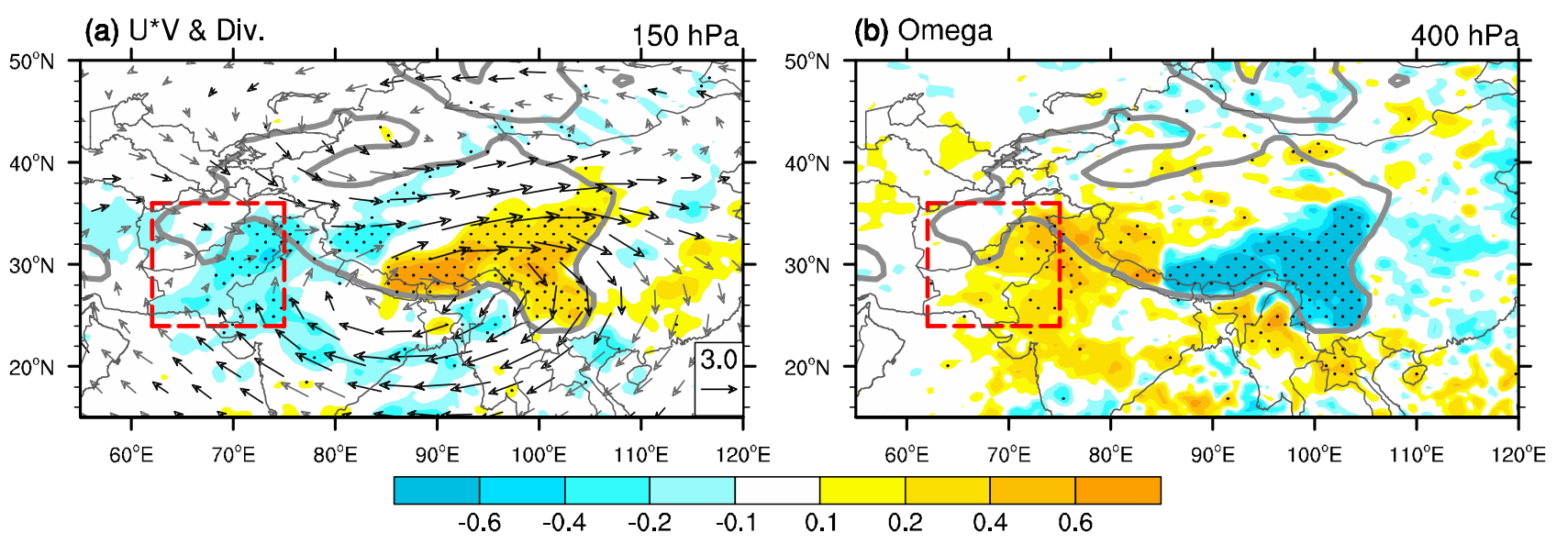

(c) Vertical flow

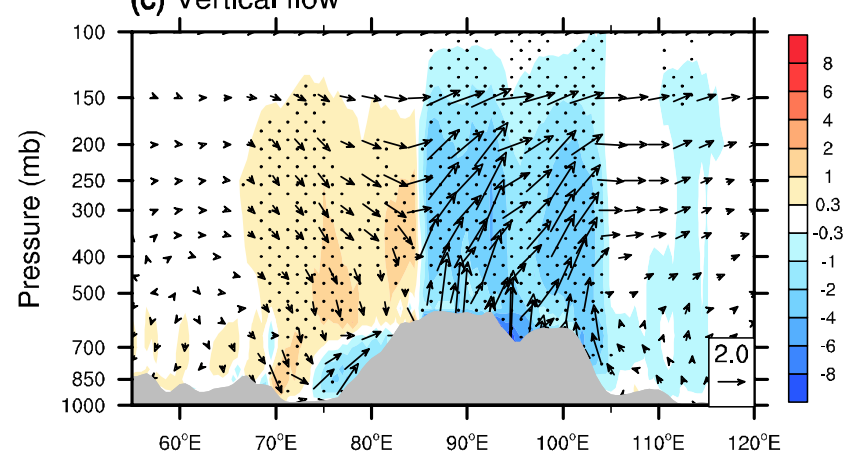

Fig. 7 a Differences in July-August mean 150-hPa wind (vectors, unit: $\mathrm{m} \mathrm{s}^{-1}$ ) and divergence (shading, unit: $10^{-5} \mathrm{~s}^{-1}$ ) between positive (TPHp) and negative (TPHn) TP heating experiments with the WRF model. b As in a, but for the 400-hPa vertical velocity (unit: $0.05 \mathrm{~Pa}$ $\mathrm{s}^{-1}$ ). c As in a, but for the pressure-longitude cross sections of vertical circulation (vectors, $\mathrm{v}$ and $-50 * \omega$, unit: $0.02 \mathrm{~m} \mathrm{~Pa} \mathrm{~s}^{-2}$ ) and verti-

troposphere (Fig. 8a). Less water vapor is thus transported into Pakistan from the Bay of Bengal, and evident divergence of moisture flux appears over Pakistan and its adjacent areas (Fig. 8b). These modeling results are also exactly similar with those from the corresponding data analyses (Fig. 4c, d). Therefore, based on the comparison between the sensitivity experiments of positive and negative heating over the southeastern TP, we have demonstrated that the TP heating can significantly regulate the Pakistan monsoon rainfall in July-August (Fig. 8a). In more detail, the TP heating drives the interannual variation of Pakistan rainfall mainly through changing both dynamic and thermodynamic conditions.

\section{Summary and discussion}

Based on data analysis and modeling study, we have examined the potential impact of TP heating on the interannual variability of Pakistan monsoon rainfall. The observed results indicate that a significant negative relationship exists cal velocity (shading, unit: $0.02 \mathrm{~Pa} \mathrm{~s}^{-1}$ ) averaged from $28^{\circ} \mathrm{N}$ to $32^{\circ} \mathrm{N}$. Stippling indicates the values $>90 \%$ confidence level for the variables represented by shading in $\mathbf{a}-\mathbf{c}$, and the vectors significantly above the $90 \%$ confidence level are plotted in black color in a. The bold gray lines denote the topographic height of $1500 \mathrm{~m}$ and the dashed red box denotes the general region of Pakistan in $\mathbf{a}-\mathbf{b}$

between the thermal forcing over southeastern TP and Pakistan monsoon rainfall in July-August. Through the further data diagnoses and model sensitivity experiments, the associated physical mechanism has been clarified.

Positive TP heating forces a Rossby wave train at the upper troposphere characterized with an anticyclonic anomaly over the southern TP but a cyclonic anomaly to the north. This dipole pattern of anomalous circulation leads to evident upper-level convergence over Pakistan, corresponding with remarkable vertical sinking motion. In addition, the TP heating also induces anomalous low-level westerly winds along the Himalayas over the northern India continent. Such westerly anomalies further weaken water vapor transport into Pakistan from the Bay of Bengal. Therefore, when the thermal forcing over the southeastern TP is strong, both dynamic and thermodynamic conditions tend to weaken the monsoon rainfall in Pakistan. This study proposes a new mechanism of the interannual variability of Pakistan monsoon rainfall.

According to previous studies (e.g., Zhao and Chen 2001a; Zhang et al. 2004; Chow et al. 2008; Duan et al. 2011; Si and Ding 2013; Wang et al. 2014; Xiao and Duan 

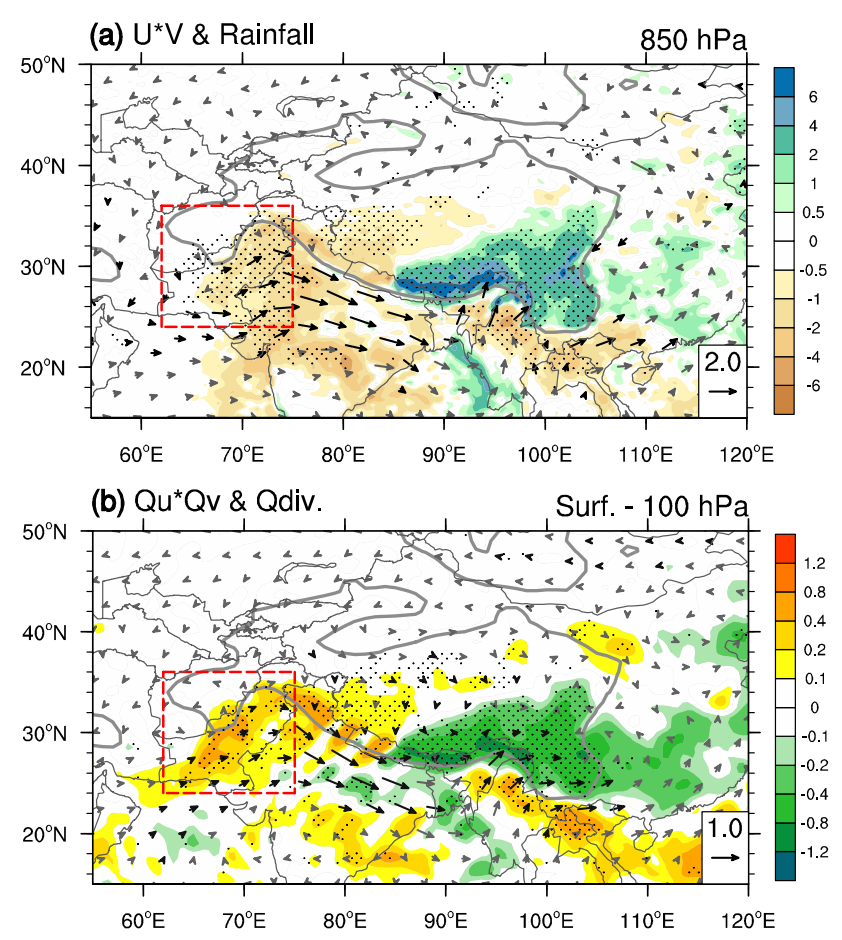

Fig. 8 As in Fig. 7, but $\mathbf{a}$ is $850-\mathrm{hPa}$ wind (vectors, unit: $\mathrm{m} \mathrm{s}^{-1}$ ) and rainfall (shading, unit: $\mathrm{mm} \mathrm{day}^{-1}$ ) and $\mathbf{b}$ is the vertically integrated (1000-100 hPa) moisture flux transport (vectors, unit: $\mathrm{kg} \mathrm{m}^{-1} \mathrm{~s}^{-1}$ ) and the corresponding divergence (shading, unit: $10^{-6} \mathrm{~kg} \mathrm{~m}^{-2} \mathrm{~s}^{-1}$ )

2016), the summer heat source over the TP is related to antecedent conditions of snow cover, soil moisture or surface sensible heat. For example, the spring sensible heat anomaly over the TP can maintain its impact until summer and lead to a strong atmospheric heat source, characterized by both enhanced sensible heat over the western TP and enhanced latent heat release to the southeast (Wang et al. 2014). Thus, an accurate antecedent factor that can reasonably represent the summer TP heating will improve the skill of seasonal prediction of Pakistan summer monsoon rainfall.

Additionally, it is worth to point out that in this study we have just emphasized the features on interannual time scale; however, the quasi-stationary synoptic disturbances over the TP also enable flooding in Pakistan through anomalous easterly flow (Rasmussen et al. 2015). Are the synoptic disturbances over the TP related with the local heating effect? What is the possible connection between TP heating and Pakistan rainfall event on the synoptic time scale? Furthermore, the tropical monsoon surge and depressions were reviewed to be important factors regulating Pakistan summer rainfall in the introduction section. While monsoon surge and depressions undoubtedly would be influenced by tropical oceanic forcing. Thus, the possible collaborative impact of TP heating and tropical oceanic forcing on the Pakistan monsoon rainfall remains unclear.
Overall, these above are interesting questions that remain for future investigations.

Acknowledgements We are grateful to the anonymous reviewers who provided thoughtful comments and valuable suggestions on this paper. This work was supported jointly by the National Natural Science Foundation of China (Grants 41605038, 91637208, 41725018 and 41661144019) and the "111-Plan" Project of China (Grant B17049). The rain gauge data used in this study is from PMD, and provided by the coauthor Kalim Ullah (kalim_ullah@comsats.edu.pk). The GPCC data set is obtained from https://www.esrl.noaa.gov/psd/data/gridded/ data.gpcc.html. And the JRA-55 reanalysis data set is available from http://jra.kishou.go.jp/JRA-55/index_en.html. Computing resource for the WRF was provided by the high-performance grid computing platform of Sun Yat-sen University and the "Tianhe-2" in the National Supercomputer Centre in Guangzhou, China.

Open Access This article is distributed under the terms of the Creative Commons Attribution 4.0 International License (http://creativeco mmons.org/licenses/by/4.0/), which permits unrestricted use, distribution, and reproduction in any medium, provided you give appropriate credit to the original author(s) and the source, provide a link to the Creative Commons license, and indicate if changes were made.

\section{References}

Adnan S, Ullah K, Gao S (2016) Investigations into precipitation and drought climatologies in south central Asia with special focus on Pakistan over the period 1951-2010. J Clim 29:6019-6035

Bollasina M, Nigam S (2011) The summertime "heat" low over Pakistan/northwestern India: evolution and origin. Clim Dyn 37:957-970

Boos W, Kuang Z (2010) Dominant control of the South Asian monsoon by orographic insulation versus plateau heating. Nature 463:218-223

Chow KC, Chan JCL, Shi XL, Liu YM, Ding YH (2008) Time-lagged effects of spring Tibetan Plateau soil moisture on the monsoon over China in early summer. Int J Climatol 28:55-67

Duan AM, Wu GX (2005) Role of the Tibetan Plateau thermal forcing in the summer climate patterns over subtropical Asia. Clim Dyn 24:793-807

Duan AM, Li F, Wang MR, Wu GX (2011) Persistent weakening trend in the spring sensible heat source over the Tibetan Plateau and its impact on the Asian summer monsoon. J Clim 24:5671-5682

Duan AM, Wu GX, Liu YM, Ma YM, Zhao P (2012) Weather and climate effects of the Tibetan Plateau. Adv Atmos Sci 29:978-992

Galarneau TJ, Hamill TM, Dole RM, Perlwitz J (2012) A multiscale analysis of the extreme weather events over western Russia and northern Pakistan during July 2010. Mon Weather Rev 140:1639-1663

Gao Y, Xiao L, Chen D, Chen F, Xu J, Xu Y (2016) Quantification of the relative role of land-surface processes and large-scale forcing in dynamic downscaling over the Tibetan Plateau. Clim Dyn 48:1705-1721

Hong C-C, Hsu H-H, Lin N-H, Chiu H (2011) Roles of European blocking and tropical-extratropical interaction in the 2010 Pakistan flooding. Geophys Res Lett 38:L13806

Houze R, Rasmussen K, Medina S, Brodzik S, Romatschke U (2011) Anomalous atmospheric events leading to the summer 2010 floods in Pakistan. Bull Am Meteorol Soc 92(3):291-298

$\mathrm{Hu}$ J, Duan A (2015) Relative contributions of the Tibetan Plateau thermal forcing and the Indian Ocean sea surface temperature 
basin mode to the interannual variability of the East Asian summer monsoon. Clim Dyn 45:2697-2711

Hussain M, Lee S (2016) Investigation of summer monsoon rainfall variability in Pakistan. Meteorol Atmos Phys 128:465-475

Jiang X, Ting M (2017) A Dipole pattern of summertime rainfall across the Indian subcontinent and the Tibetan Plateau. J Clim 30:9607-9620

Jiang X, Li Y, Yang S, Yang K, Chen J (2016) Interannual variation of summer atmospheric heat source over the Tibetan Plateau and the role of convection around the western maritime continent. J Clim 29:121-138

Kitoh A (2004) Effects of mountain uplift on East Asian summer climate investigated by a coupled atmosphere-ocean GCM experiments. J Clim 17:783-802

Kobayashi S, Ota Y, Harada Y, Ebita A, Moriya M, Onoda H, Onogi K, Kamahori H, Kobayashi C, Endo H, Miyaoka K, Takahashi K (2015) The JRA-55 reanalysis: general specifications and basic characteristics. J Meteorol Soc Jap 93:5-48

Latif M, Syed FS, Hannachi A (2017) Rainfall trends in the South Asian summer monsoon and its related large-scale dynamics with focus over Pakistan. Clim Dyn 48:3565-3581

Lau W, Kim K-M (2012) The 2010 Pakistan flood and Russian heat wave: teleconnection of hydrometeorological extremes. J Hydrometeorol 13:392-403

Okajima H, Xie S-P (2007) Orographic effects on the northwestern Pacific monsoon: role of air-sea interaction. Geophys Res Lett 34:L21708

Raju A, Parekh A, Chowdary JS, Gnanaseelan C (2015) Assessment of the Indian summer monsoon in the WRF regional climate model. Clim Dyn 44:3077-3100

Rasmussen K, Hill A, Toma V, Zuluaga M, Webster P, Houze R (2015) Multiscale analysis of three consecutive years of anomalous flooding in Pakistan. Q J R Meteorol Soc 141:1259-1276

Reynolds RW, Smith TM, Liu C, Chelton DB, Casey KS, Schlax MG (2007) Daily high-resolution-blended analyses for sea surface temperature. J Clim 20:5473-5496

Schneider U, Becker A, Finger P, Meyer-Christoffer A, Ziese M, Rudolf B (2014) GPCC's new land surface precipitation climatology based on quality-controlled in situ data and its role in quantifying the global water cycle. Theor Appl Climatol 115:15-40

Si D, Ding Y (2013) Decadal change in the correlation pattern between the Tibetan Plateau winter snow and the East Asian summer precipitation during 1979-2011. J Clim 26:7622-7634

Skamarock WC, Klemp JB, Dudhia J, Gill DO, Barker D, Duda MG, Huang XY, Wang W (2008) A description of the advanced research WRF version 3. NCAR Technical Note NCAR/TN-475 + STR. NCAR, Boulder. https://doi.org/10.5065/D68S4MVH

Wang B, Bao Q, Hoskins B, Wu GX, Liu YM (2008) Tibetan Plateau warming and precipitation changes in East Asia. Geophys Res Lett 35:L14702. https://doi.org/10.1029/2008GL034330

Wang Z, Duan A, Wu G (2014) Time-lagged impact of spring sensible heat over the Tibetan Plateau on the summer rainfall anomaly in East China: case studies using the WRF model. Clim Dyn 42:2885-2898
Wang Z, Duan A, Li M, He B (2016) Influences of thermal forcing over the slope/platform of the Tibetan Plateau on Asian summer monsoon: numerical studies with WRF model. Chin J Geophys 59(5):474-487

Wang Z, Duan A, Yang S, Ullah K (2017a) Atmospheric moisture budget and its regulation on the variability of summer precipitation over the Tibetan Plateau. J Geophys Res 122:614-630

Wang Z, Li G, Yang S (2017b) Origin of Indian summer monsoon rainfall biases in CMIP5 multimodel ensemble. Clim Dyn. https ://doi.org/10.1007/s00382-017-3953-x

Wang Z, Duan A, Yang S (2018) Potential regulation on the climatic effect of Tibetan Plateau heating by tropical air-sea coupling in regional models. Clim Dyn. https://doi.org/10.1007/s0038 $2-018-4218-Z$

Webster P, Toma V, Kim H-M (2011) Were the 2010 Pakistan floods predictable? Geophys Res Lett 38:L04806

Wilks DS (1995) Statistical methods in the atmospheric sciences. Academic Press, Cambridge, pp 216-218

Wu G, Liu Y, Wang T, Wan R, Liu X, Li W, Wang Z, Zhang Q, Duan A, Liang $X$ (2007) The influence of the mechanical and thermal forcing of the Tibetan Plateau on the Asian climate. J Hydrometeorol 8:770-789

Wu G, Liu Y, He B, Bao Q, Duan A, Jin F (2012) Thermal controls on the Asian summer monsoon. Sci Rep 2:404

Wu G, Zhuo H, Wang Z, Liu Y (2016) Two types of summertime heating over the Asian large-scale orography and excitation of potential-vorticity forcing I. over the Tibetan Plateau. Sci China Earth Sci 59:1996-2008

Xiao Z, Duan A (2016) Impacts of Tibetan Plateau snow cover on the interannual variability of the East Asian summer monsoon. J Clim 29:8495-8514

Yamada T, Takeuchi D, Farukh M, Kitano Y (2016) Climatological characteristics of heavy rainfall in northern Pakistan and atmospheric blocking over western Russia. J Clim 29:7743-7754

Yanai M, Wu G (2006) Effects of the Tibetan Plateau. In: Wang B (ed) The Asian monsoon. Springer Praxis, Berlin, pp 513-549

Ye D, Gao Y (1979) Tibetan Plateau meteorology (in Chinese). Science Press, Beijing

Zhang Y, Li T, Wang B (2004) Decadal change of the spring snow depth over the Tibetan Plateau: the associated circulation and influence on the East Asian summer monsoon. J Clim 17:2780-2793

Zhao P, Chen LX (2001a) Interannual variability of atmospheric heat source/sink over the Qinghai-Xizang (Tibetan) Plateau and its relation to circulation. Adv Atmos Sci 18:106-116

Zhao P, Chen LX (2001b) Climate features of atmospheric heat source/ sink over the Qinghai-Xizang Plateau in 35 years and its relation to rainfall in China. Sci China Ser D 44:858-864

Zuo Z, Zhang R, Zhao P (2011) The relation of vegetation over the Tibetan Plateau to rainfall in China during the boreal summer. Clim Dyn 36:1207-1219 